\section{Brazilian Journal \\ of Chemical \\ Engineering}

ISSN 0104-6632

Printed in Brazil

www.scielo.br/bjce

Vol. 35, No. 01, pp. 189 - 195, January - March, 2018

(cc) BY

dx.doi.org/10.1590/0104-6632.20180351s20160146

\title{
LITHIUM CONTAINING MgAl MIXED OXIDES OBTAINED FROM SOL-GEL HYDROTALCITE FOR TRANSESTERIFICATION
}

\author{
Renata A. B. Lima-Corrêa ${ }^{1,2, *}$, Cínthia S. Castro³, José M. Assaf ${ }^{1}$ \\ ${ }^{1}$ Chemical Engineering Department, Federal University of São Carlos, Rodovia Washington Luís, km 235, \\ CEP 13565-905, São Carlos, SP, Brazil. \\ ${ }^{2}$ Engineering Department, Federal University of Lavras, Campus Universitário, PO Box 3037, CEP 37200-000, Lavras, MG, Brazil. \\ ${ }^{3}$ Science and Technology Institute, Federal University of Alfenas, Rodovia José Aurélio Vilela, 11999, BR 267, km 533,
} CEP 37715-400, Poços de Caldas, MG, Brazil.

(Submitted: January 15, 2016; Revised: December 1, 2016; Accepted: December 15, 2016)

\begin{abstract}
The innumerous advantages of heterogeneous catalysts employed in biodiesel production have stimulated the search for a solid catalyst capable of replacing the industrially used homogeneous catalysts. This paper investigates the effect of the sol-gel method in the catalytic activity and stability of Li-MgAl mixed oxides prepared by the "in situ" lithium addition to a MgAl hydrotalcite. The analyses based on $\mathrm{N}_{2}$ physisorption, thermogravimetric analysis, $\mathrm{X}$-ray diffractometry, scanning electron microscopy and temperature-programmed desorption of $\mathrm{CO}_{2}$ were carried out to elucidate the properties of the catalysts. Considerable differences in the physico-chemical properties of the catalysts were observed with the Li addition. Li reduced the surface area and increased the crystallite size of the oxides. Furthermore, $\mathrm{Li}-\mathrm{MgAl}$ mixed oxides prepared by the calcination of the sol-gel MgAl hydrotalcites presented substantial morphological differences when compared to the same oxides obtained by heat treatment of hydrotalcites synthesized via the conventional co-precipitation route. Furthermore, $\mathrm{Li}$ increased the number and strength of the base sites which resulted in the increase of the oxide reactivities towards the transesterification reaction between methyl acetate and ethanol. The activity was dependent on the Li loading on the catalysts. The catalyst containing only $5 \mathrm{wt} . \%$ Li turned out to be highly active $\left(\approx 85 \%\right.$ conversion at $50^{\circ} \mathrm{C}$, ethanol $/$ methyl acetate molar ratio $=6 / 1,4$ wt. $\%$ of catalyst and $30 \mathrm{~min}$ of reaction). Stability tests showed that the Li-MgAl catalysts lose activity after 3 reuse cycles.
\end{abstract}

Keywords: hydrotalcite; sol-gel method; transesterification; lithium; mixed oxide; heterogeneous catalysis.

\section{INTRODUCTION}

In recent years there has been a growing awareness concerning the rational use of natural resources and the need to introduce pollution prevention practices, and development and use of clean technologies (Aransiola et al., 2014). As a result, extensive research has been performed in order to obtain alternatives to conventional fossil diesel fuels. One of the most attractive options is biodiesel since it is non-toxic, renewable and biodegradable. Biodiesel is usually produced from triglycerides (vegetable oils or animal fats) by a transesterification reaction with a shortchain alcohol (mainly methanol or ethanol). The reaction requires the presence of a catalyst, and homogeneous base catalysts $(\mathrm{NaOH}, \mathrm{KOH}$ or its methoxides) have been industrially employed (Bart et al., 2010). However, the use of heterogeneous catalysts has been pointed out as the main significant improvement to the process. The solid catalyst can be easily separated from the final product and there is no need of water washing to remove the catalyst, which could reduce the biofuel production cost (Hanna and Isom, 2009). 
The innumerous advantages of the heterogeneous process have stimulated the search for a solid catalyst capable of replacing those used industrially for biodiesel production. In this context, $\mathrm{MgAl}$ mixed oxides derived from hydrotalcite compounds have been evaluated as solid base catalysts for transesterification and revealed to be promising for this application (Xie et al., 2006; Di Serio et al., 2012; Hájek et al., 2015). These ordinary MgAl mixed oxides have also been modified by incorporation of metal ions such as $\mathrm{Na}^{+}$and $\mathrm{K}^{+}$(Tittabut and Trakarnpruk, 2008), $\mathrm{Fe}^{3+}$ (Wang et al., 2012), $\mathrm{Co}^{2+}, \mathrm{Cu}^{2+}, \mathrm{Cr}^{3+}$ and $\mathrm{Fe}^{3+}$ (Veiga et al., 2013), and $\mathrm{Zn}^{2+}, \mathrm{Co}^{2+}, \mathrm{Fe}^{3+}$ and $\mathrm{La}^{3+}$ (Sun et al., 2014) in order to tailor the catalyst acid-base properties and consequently its performance for transesterification. Recent studies have also been dedicated to evaluate the effect of introducing non-metal species, such as fluorine (Lima et al., 2012), and also KF salt (Guzmán-Vargas et al., 2015), in the textural and basic properties and/or catalytic activity for transesterification of mixed oxides obtained from hydrotalcite-like compounds. For KF-modified CaAl hydrotalcites, Chen et al. (2014) investigated the influence of the impregnation solvent on the catalytic activity. They found that the catalysts synthesized in methanol displayed excellent activity for transesterification.

An inspection of published papers focused on metalbased MgAl mixed oxides shows that most authors adopt a similar procedure for synthesis of such catalysts, in which the $\mathrm{MgAl}$ oxides are obtained by the thermal treatment of $\mathrm{MgAl}$ hydrotalcite synthesized by a co-precipitation route. Therefore, this project was undertaken to evaluate the effect of the sol-gel method in the synthesis of MgAl hydrotalcite and the catalytic activity and stability of the obtained $\mathrm{MgAl}$ mixed oxides modified by $\mathrm{Li}$ for transesterification. The sol-gel method enables a high degree of control over the catalyst preparation, which allows the catalyst properties to be "molded" by varying the process parameters such as $\mathrm{pH}$, reaction time and temperature, type of solvent and metal precursor used. Furthermore, the synthesis of catalysts by the sol-gel method allows the direct addition of the metal precursor in situ during the process. To the extent of our knowledge, there is no other paper in the literature that describes the synthesis of $\mathrm{MgAl}$ mixed oxides modified by Li obtained from sol-gel hydrotalcites.

\section{MATERIALS AND METHODS}

\section{Synthesis of the catalysts}

A sol-gel method based on Prinetto et al. (2000) was used to synthesize hydrotalcite (HT) compounds with a Mg/ $\mathrm{Al}$ molar ratio of 4 . Briefly, $0.15 \mathrm{~mol}$ of $\mathrm{Mg}\left(\mathrm{NO}_{3}\right)_{2} \cdot 6 \mathrm{H}_{2} \mathrm{O}$ (Sigma-Aldrick) was dissolved in $120 \mathrm{~mL}$ of ethanol (Synth, 99.5\% v/v) containing $3.2 \mathrm{~mL}$ of $\mathrm{HCl}$ (Baker, $35 \% \mathrm{v} / \mathrm{v})$. Another solution containing $0.038 \mathrm{~mol}$ of
$\mathrm{Al}\left(\mathrm{NO}_{3}\right)_{3} \cdot 9 \mathrm{H}_{2} \mathrm{O}$ (Synth) dissolved in $80 \mathrm{~mL}$ of ethanol was added under constant stirring. The final $\mathrm{pH}$ of the mixture was adjusted to 10 by the dropwise addition of $\mathrm{NH}_{4} \mathrm{OH}$ (Mallinckrodt Chemicals, 30\% v/v). The resulting mixture was then constantly stirred until the gel formation $(24 \mathrm{~h})$. The obtained gel was repeatedly washed with distilled water and oven dried at $80^{\circ} \mathrm{C}$ for $24 \mathrm{~h}$.

The Li-based catalysts were prepared by using a similar method described for $\mathrm{MgAl}$ hydrotalcite synthesis. However, the precursor of the $\mathrm{Li}^{+}$was added in situ. For that, $\mathrm{LiNO}_{3}$ (Acros Organics, 99+\%) was dissolved in 60 $\mathrm{mL}$ of ethanol and added to the mixture just before the $\mathrm{pH}$ adjusting. After $24 \mathrm{~h}$ of stirring, the obtained gel was oven dried at $80^{\circ} \mathrm{C}$ for $24 \mathrm{~h}$. The catalysts were prepared at the lithium loadings of 3, 5, 10 and $15 \mathrm{wt} . \%\left[\mathrm{Li}^{+} /\left(\mathrm{Li}^{+}+\right.\right.$mixed oxide)]. It must be mentioned that the mixed oxide weight was established by TGA analyses at the desired calcination temperature. The $\mathrm{MgAl}$ and $\mathrm{Li}-\mathrm{MgAl}$ mixed oxides were prepared by the calcination of the $\mathrm{HT} \mathrm{MgAl}$ and $\mathrm{Li}^{+}$ containing HTs, respectively. The thermal treatment was performed under air atmosphere in an EDG oven (3P-S 1800 ) at a heating rate of $5^{\circ} \mathrm{C} \mathrm{min}^{-1}$ from room temperature up to $600^{\circ} \mathrm{C}$ and kept for $2 \mathrm{~h}$ at this temperature. The catalysts were named $\mathrm{MgAl}$ and $\mathrm{x} \mathrm{Li}-\mathrm{MgAl}$, where ' $\mathrm{x}$ ' is the lithium loading expressed in wt.\%.

\section{Characterization of the materials}

The materials were characterized by powder X-ray diffractometry in a Rigaku Multiflex using $\mathrm{Cu} \mathrm{K} \alpha$ radiation $\left(\lambda=1.5406 \AA\right.$ ) in the range $2 \theta$ from $5^{\circ}$ to $80^{\circ}$, with a scan rate of $2^{\circ} \mathrm{min}^{-1}$ and a step width of $0.02^{\circ}$. The crystalline phases were identified using the Powder Diffraction File (PDF) database of the Joint Committee on Powder Diffraction Standards (JCPDS). The oxides crystallite sizes were calculated by the Scherrer equation using the main diffraction peak $\left(2 \theta \approx 43^{\circ}\right)$ from the $(200) \mathrm{MgO}$ plane. Thermogravimetric analyses were carried out using a Shimadzu DTG-60H equipment (simultaneous DTA-TG apparatus). The samples were heated at a rate of $10^{\circ} \mathrm{C} \mathrm{min}^{-1}$ from room temperature to $1000^{\circ} \mathrm{C}$ under an air flow of 50 $\mathrm{mL} \mathrm{min}^{-1}$. Surface areas (BET method), pore volumes (BJH method applied to desorption isotherms) and the pore size distributions of the calcined samples were determined by $\mathrm{N}_{2}$ physisorption at $77 \mathrm{~K}$ in a Quantachrome NOVA 1200. The morphology of the catalysts was characterized by scanning electron microscopy (SEM) on a FEI Magellan 400 L microscope. A Varian SpectrAA-200 atomic emission spectrometer was used to measure the lithium concentration in the catalysts (after calcination). For that, duplicate samples were digested with a mixture of $\mathrm{HCl}$ (Quimis, 37\% v/v) and $\mathrm{HNO}_{3}$ (Synth, 65\% v/v), and $\mathrm{H}_{2} \mathrm{O}_{2}$ (Synth, 29\% v/v) was used as an auxiliary oxidizing agent.

The basic properties of the catalysts were determined by temperature programmed desorption of $\mathrm{CO}_{2}$ (TPD of 
$\mathrm{CO}_{2}$ ) in an AutoChem II chemisorption analyzer equipped with thermal conductivity detector (TCD). The samples $(100 \mathrm{mg})$ were pretreated under He flow $\left(50 \mathrm{~mL} \mathrm{\textrm {min } ^ { - 1 } )}\right.$ until the corresponding calcination temperature $\left(\mathrm{T}=600^{\circ} \mathrm{C}\right)$ with a heating rate of $20^{\circ} \mathrm{C} \mathrm{min}^{-1}$ and then cooled to $100^{\circ} \mathrm{C}$. The $\mathrm{CO}_{2}$ adsorption was performed at $100^{\circ} \mathrm{C}$ for $1 \mathrm{~h}$ using

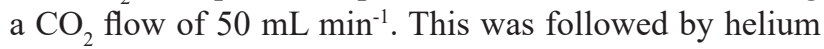
purge (flow of $30 \mathrm{~mL} \mathrm{~min}^{-1}$, temperature of $100^{\circ} \mathrm{C}$ for $1 \mathrm{~h}$ ) to remove weakly adsorbed $\mathrm{CO}_{2}$. The samples were cooled to $50^{\circ} \mathrm{C}$ and the $\mathrm{CO}_{2}$ desorption profiles were obtained by heating the samples from 50 to $600^{\circ} \mathrm{C}$, under $\mathrm{He}(30 \mathrm{~mL}$

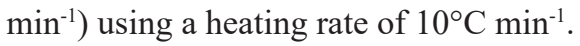

\section{Catalytic tests}

The catalytic activity was evaluated in the transesterification model reaction between methyl acetate (Vetec, 99\% v/v) and ethanol (Synth, 99.5\% v/v). Compared to the transesterification reaction of vegetable oils, the model reaction is easier to perform and the formed products (methanol and ethyl acetate) are quickly monitored by gas chromatography (run time $\approx 4.3 \mathrm{~min}$ ). It is worth mentioning that ethanol was selected as the alcohol source due to its renewable origin.

The experiments were carried out under optimized conditions with detailed description elsewhere (Castro et al., 2011; Castro et al., 2014). In short, the catalytic tests were performed in triplicate in small batch reactors with magnetic stirring, using an ethanol/methyl acetate mol ratio of $6 / 1$, catalyst loading of 4 wt. $\%$ (wt. catalyst/ wt. of the reaction mixture), temperature of $50^{\circ} \mathrm{C}$ and 30 min of reaction. The reaction products were analyzed in a Shimadzu gas chromatograph (GC 2010) equipped with flame ionization detector (FID) and $\mathrm{Rtx}^{\circledR}$-1 capillary column ( $30.0 \mathrm{~m} \times 0.32 \mathrm{~mm}$ i.d. $\times 3.00 \mu \mathrm{m}$ film thicknesses). Column, injector and detector temperatures were held, respectively, at $65^{\circ} \mathrm{C}, 150^{\circ} \mathrm{C}$ and $170^{\circ} \mathrm{C}$. Helium was used as carrier gas at a linear velocity of $40.0 \mathrm{~cm} . \mathrm{s}^{-1}$ and 1.0 $\mu \mathrm{L}$ samples were injected manually in the split mode (ratio $1: 150$ ).

The catalytic activity was also expressed in terms of the turnover frequency (TOF), calculated as the number of moles of methyl acetate converted per active basic site per second of reaction. It is important to mention that the TOF was calculated considering only the strong basic sites detected by TPD of $\mathrm{CO}_{2}$, since the weak basic sites of the $\mathrm{Mg}(\mathrm{Al}) \mathrm{O}$ catalyst were not active for transesterification reaction under the studied conditions (see Table 2).

\section{Stability tests}

The reuse of the catalysts in different batches was investigated. After reaction, the solid catalyst was separated from the reaction mixture by centrifugation. The supernatant solution was carefully removed and analyzed by GC. Anew reaction mixture was then placed to react with the used catalyst. This process was repeated for subsequent reuse cycles and all reactions were performed under the same conditions described for catalytic evaluation. The reuse assays were also performed in triplicate. It should be highlighted that the basic catalysts were not washed nor dried in order to avoid their contact with atmospheric air, thereby preventing carbonation of the material.

In addition, chemical analysis of the reaction mixture was carried out in order to verify the occurrence of $\mathrm{Li}$ leaching from the catalyst to the solution. For that, the solution was filtered after the first reaction cycle by using syringe filters $(0.45 \mu \mathrm{m}$ pore size $)$, the volatile compounds were evaporated and the residual metals were resuspended with $\mathrm{HNO}_{3}$ solution $(1 \% \mathrm{v} / \mathrm{v})$ for the chemical analysis in a Varian SpectrAA-200 Atomic Emission Spectrometer.

\section{RESULTS AND DISCUSSION}

\section{Characterization of the catalysts}

The structure of the catalysts was investigated by XRD. The XR diffractions of the sol-gel MgAl hydrotalcite are shown in Fig. 1-a and attest to the formation of the hydrotalcite lamellar structure [JCPDF 14-0191]. Figure 1-b presents the XRD of the MgAl mixed oxide and Li$\mathrm{MgAl}$. As expected, the heat treatment of the hydrotalcite generated a MgAl mixed oxide with periclase structure $(\mathrm{MgO})$ [JCPDS 75-1525]. No $\mathrm{AlO}_{\mathrm{x}}$ cristalline phases were detected, which suggests the formation of a solid solution between $\mathrm{MgO}$ and $\mathrm{AlO}_{\mathrm{x}}$ during calcination. In fact, the ionic radii of $\mathrm{Mg}^{2+}(0.72 \AA)$ and $\mathrm{Al}^{3+}(0.53 \AA)$ are not so different (Lide, 1997; Barbosa et al., 2005) and the incorporation of $\mathrm{Al}^{3+}$ ions into $\mathrm{MgO}$ creates defects within the $\mathrm{MgO}$ lattice and causes structural promotion at high temperature during calcination (Di Cosimo et al., 1998).

In the case of the $\mathrm{Li}-\mathrm{MgAl}$ oxides, the similar ionic radii of $\mathrm{Li}^{+}(0.76 \AA)$ and $\mathrm{Mg}^{2+}(0.72 \AA)$ allows the $\mathrm{Mg}^{2+}$ substitution by $\mathrm{Li}^{+}$ions into the $\mathrm{MgO}$ lattice during calcination. The substitution of divalent by monovalent cations leads to the formation of $\mathrm{O}^{2-}$ anions of low coordination. These $\mathrm{O}^{2-}$ anions are located at the corners and edges of the $\mathrm{MgO}$ crystals and have high basic strength (Di Cosimo et al., 1998; Díez et al., 2006; Berger et al., 2007). In addition to that, some low intensity diffractions possibly indicate the presence of $\mathrm{LiAlO}_{2}, \mathrm{Li}_{2} \mathrm{CO}_{3}$ and $\mathrm{LiOH}$ in the $\mathrm{Li}-\mathrm{MgAl}$ oxides. The $\mathrm{Li}_{2} \mathrm{CO}_{3}$ and $\mathrm{LiOH}$ are probably formed from carbonatation and hydration of $\mathrm{Li}_{2} \mathrm{O}$, respectively. This can be the reason for the absence of diffractions related to the $\mathrm{Li}_{2} \mathrm{O}$ compound. $\mathrm{Li}_{2} \mathrm{O}$ was expected to be present in the $\mathrm{Li}-\mathrm{MgAl}$ mixed oxides since this compound is generated during the thermal decomposition of $\mathrm{LiNO}_{3}$ used in the synthesis procedure. The $\mathrm{Li}_{2} \mathrm{O}$ can also be present in small particle size and/or highly dispersed over the oxide matrix. This finding is in agreement with Rynkowski et al. 
(1996) and Díez et al. (2006), who reported the absence of diffractions for $\mathrm{Li}_{2} \mathrm{O}$ for lithium promoted $\mathrm{MgO}$. Furthermore, $\mathrm{LiNO}_{3}$ diffractions (Fig. 1-b) were detected for the sample containing the highest Li loading (15 Li$\mathrm{MgAl})$, which reveals an incomplete decomposition of the lithium nitrate precursor during the calcination performed at $600^{\circ} \mathrm{C}$. However, the temperature of $600^{\circ} \mathrm{C}$ has been chosen as the calcination temperature of the catalysts in order to compare the properties and catalytic performance of the sol-gel Li-MgAl with the coprecipitated samples reported in our previous paper (Castro et al., 2011).

The thermal stability of the MgAl hydrotalcite under air atmosphere was investigated by thermogravimetric analyses (Fig 2). The TG/DTG (derivate weight loss) (Fig. 2-a) and DTA/DTG (Fig. 2-b) profiles showed representative transformations of hydrotalcite compounds (Lopez et al., 1997; Xie et al., 2006; Serrano-Lotina et al., 2011).

In Fig. 2-a and b, the first endothermic peak (centered at $\approx 137^{\circ} \mathrm{C}$, with weight loss of $\approx 12 \%$ ) can be associated with the elimination of the surface water along with the water present in the interlayer space. The weight loss of about $34 \%$ that occurred in the temperature range of 250 - $550^{\circ} \mathrm{C}$ can be related to the layer dehydroxylation and release of the anions $(-\mathrm{OH})$ present in the interlayer space. These processes lead to the collapse of the hydrotalcite structure and the formation of the MgAl mixed oxide (Xie et al., 2006; Ramos-Ramírez et al., 2009). At temperatures above $550^{\circ} \mathrm{C}$, the residual mass is almost constant, with a total weight loss of $48 \%$.

Fig. 3-a and $b$ compares the TGA profiles obtained for sol-gel hydrotalcite (before calcination) containing 5 and $15 \%$ of $\mathrm{Li}$, respectively. It can be noted that the hydrotalcite containing only $5 \% \mathrm{Li}$ (Fig. 3 -a) is completely decomposed at a temperature near $580^{\circ} \mathrm{C}$. On the other hand, for the hydrotalcite containing 15\% Li (Fig. 3-b), the complete decomposition occurs at about $650^{\circ} \mathrm{C}$. This finding attests that the Li addition into hydrotalcite induces changes in the thermal stability of the materials. The increased amount of $\mathrm{LiNO}_{3}$ on the catalysts displaces the decomposition temperature toward higher values. The total weight loss $\left(\approx 80 \%\right.$ at $1000^{\circ} \mathrm{C}$, Fig. 3 -a and b) is similar for both materials. This high weight loss observed for the Li containing hydrotalcites occurs because these samples were not washed during the synthesis procedure and all the aluminum, magnesium and lithium nitrates are eliminated during the heat treatment. Therefore, the TGA results indicate that $15 \mathrm{Li}-\mathrm{MgAl}$ is not completely decomposed during calcination performed at $600^{\circ} \mathrm{C}$ and the residual $\mathrm{LiNO}_{3}$ remains on the catalyst, thus corroborating the results obtained by XRD. However, it is already known that the residual $\mathrm{LiNO}_{3}$ is not active for transesterification (Castro et al., 2011).

The effect of the Li addition on the catalyst morphology was investigated by SEM. The MgAl (Fig. 4-a) presents typical "platelet" morphology of the mixed oxides derived from hydrotalcite (Reichle et al., 1986; Xie et al., 2006; Tittabut and Trakarnpruk, 2008). However, the $\mathrm{Li}$ addition significantly affected the morphology of the oxides. The 5 Li-MgAl (Fig. 4-b) presents aggregates of round particles and a completely different morphology can be observed for 10 and $15 \mathrm{Li}-\mathrm{MgAl}$. Fused and sintered particles with long format resembling needles along with plate forms of smooth surface can be seen for 10 Li-MgAl (Fig. 4-c). For15 Li-MgAl (Fig. 4-d), only needle forms can be observed. It must be mentioned that the sol-gel Li-MgAl morphology is rather different from the morphology of the co-precipitated $\mathrm{Li}-\mathrm{MgAl}$ oxides that present large aggregates composed of round particles (Castro et al., 2011; Castro et al., 2013).
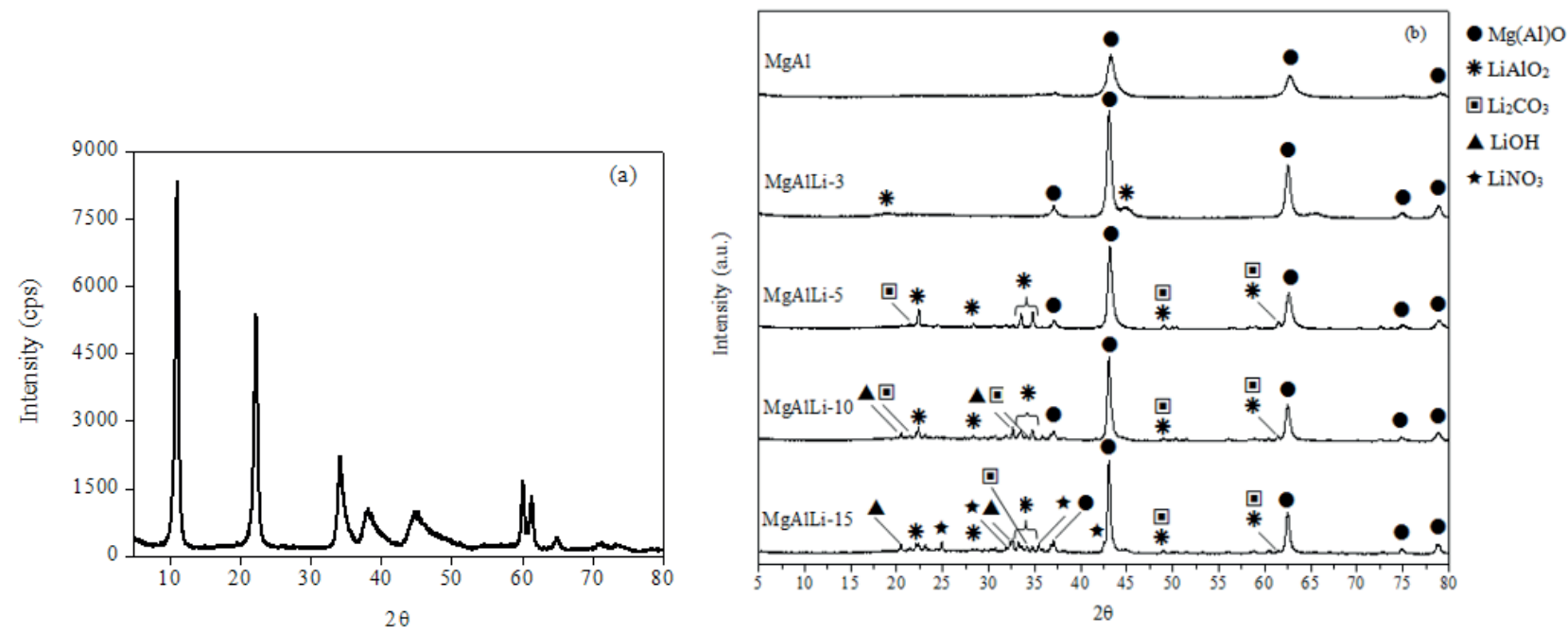

Figure 1. XRD of the sol-gel $\mathrm{MgAl}$ hydrotalcite (a) and $\mathrm{MgAl}$ and $\mathrm{Li}-\mathrm{MgAl}$ mixed oxides (b). 

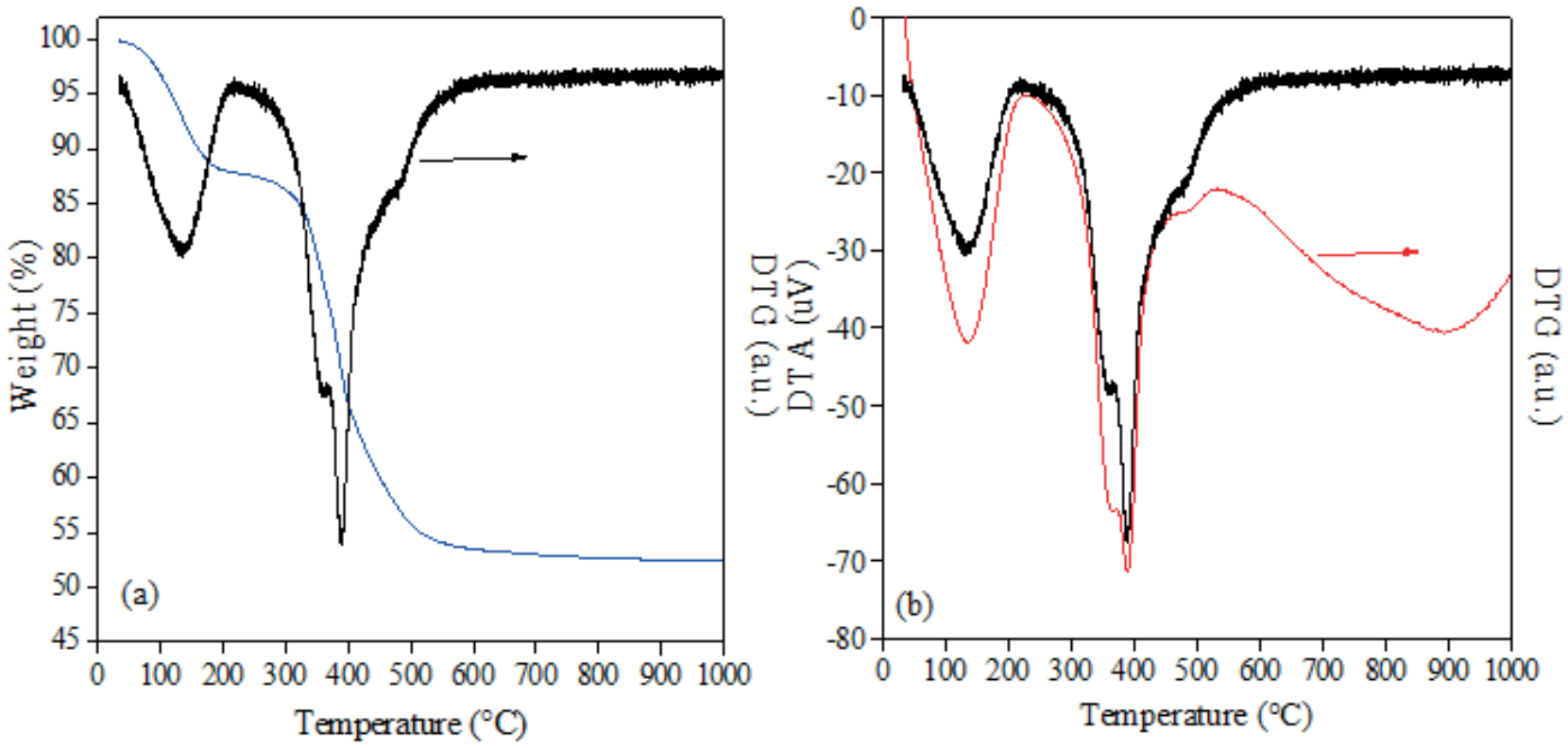

Figure 2. Thermal analysis TG/DTG (a) and DTA/DTG (b) of the sol-gel MgAl hydrotalcite.

The $\mathrm{N}_{2}$ adsorption/desorption isotherms at $77 \mathrm{~K}$ for the MgAl and Li-MgAl oxides are shown in Fig. 5-a and 5-b, respectively. All materials presented similar isotherm shapes, classified as type IV, with an H3 hysteresis loop (it was not possible to obtain the isotherms for $15 \mathrm{Li}$ $\mathrm{MgAl}$ due to its very small $\mathrm{N}_{2}$ adsorbed amount). Such isotherms are typical of mesopore-containing solids (2$50 \mathrm{~nm}$ ) (Sing et al., 1985). The presence of mesopores in the catalyst is very important when this catalyst is applied for transesterification of triglycerides. The large pores assist the reactant diffusion into the solid to reach the active sites.

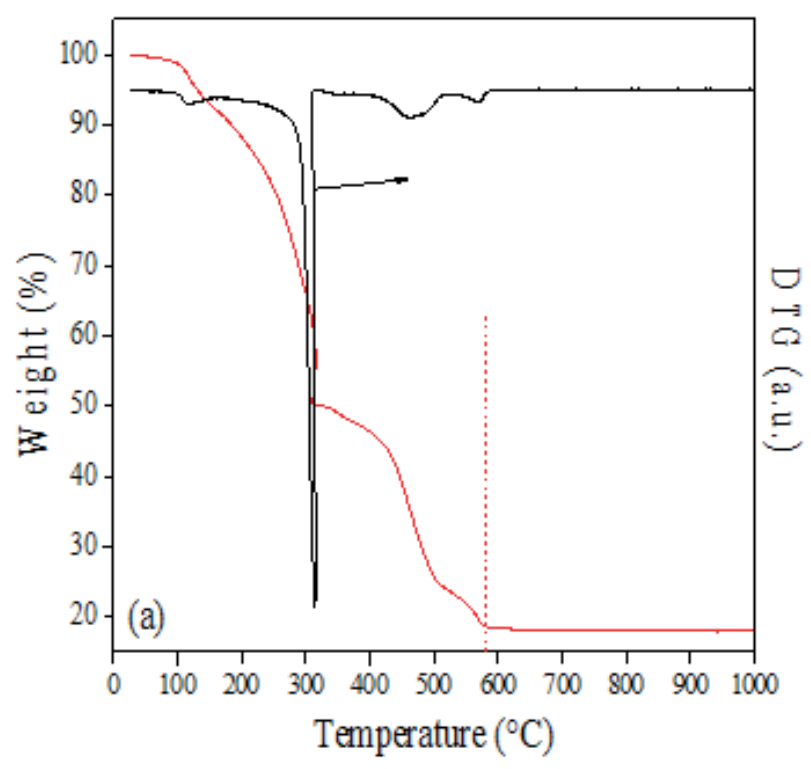

Table 1 provides the catalyst characterization such as crystallite size, BET surface area, pore volume and lithium loading in the oxides.

It is apparent from Table 1 that the crystallite size of the catalysts increases as the $\mathrm{Li}$ content increases. According to Rynkowski et al. (1996) and Berger et al. (2007), the thermal stability of $\mathrm{MgO}$ is strongly reduced in the presence of $\mathrm{Li}$, which causes oxide sintering at elevated temperatures. As the MgAl mixed oxide presents the similar cubic structure of $\mathrm{MgO}$, it is possible to infer that the $\mathrm{Li}$ addition to $\mathrm{MgAl}$ produces a similar sintering effect to that of the $\mathrm{Li}$ addition to $\mathrm{MgO}$. In consequence of

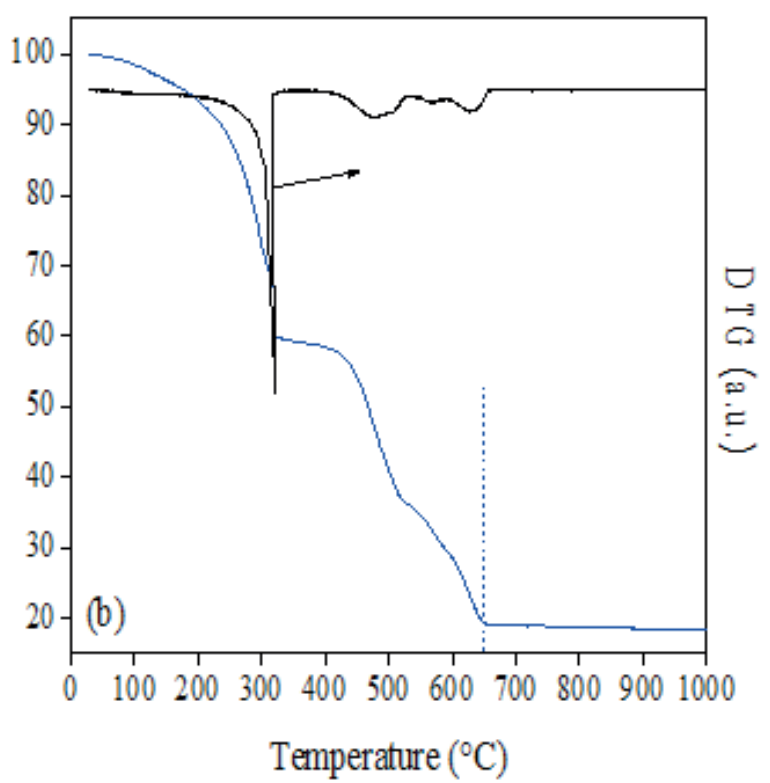

Figure 3. TG/DTG curves for the sol-gel MgAl hydrotalcite (before calcination) containing 5 wt. $\%$ of $\mathrm{Li}$ (a) and 15 wt. $\%$ of Li (b). 

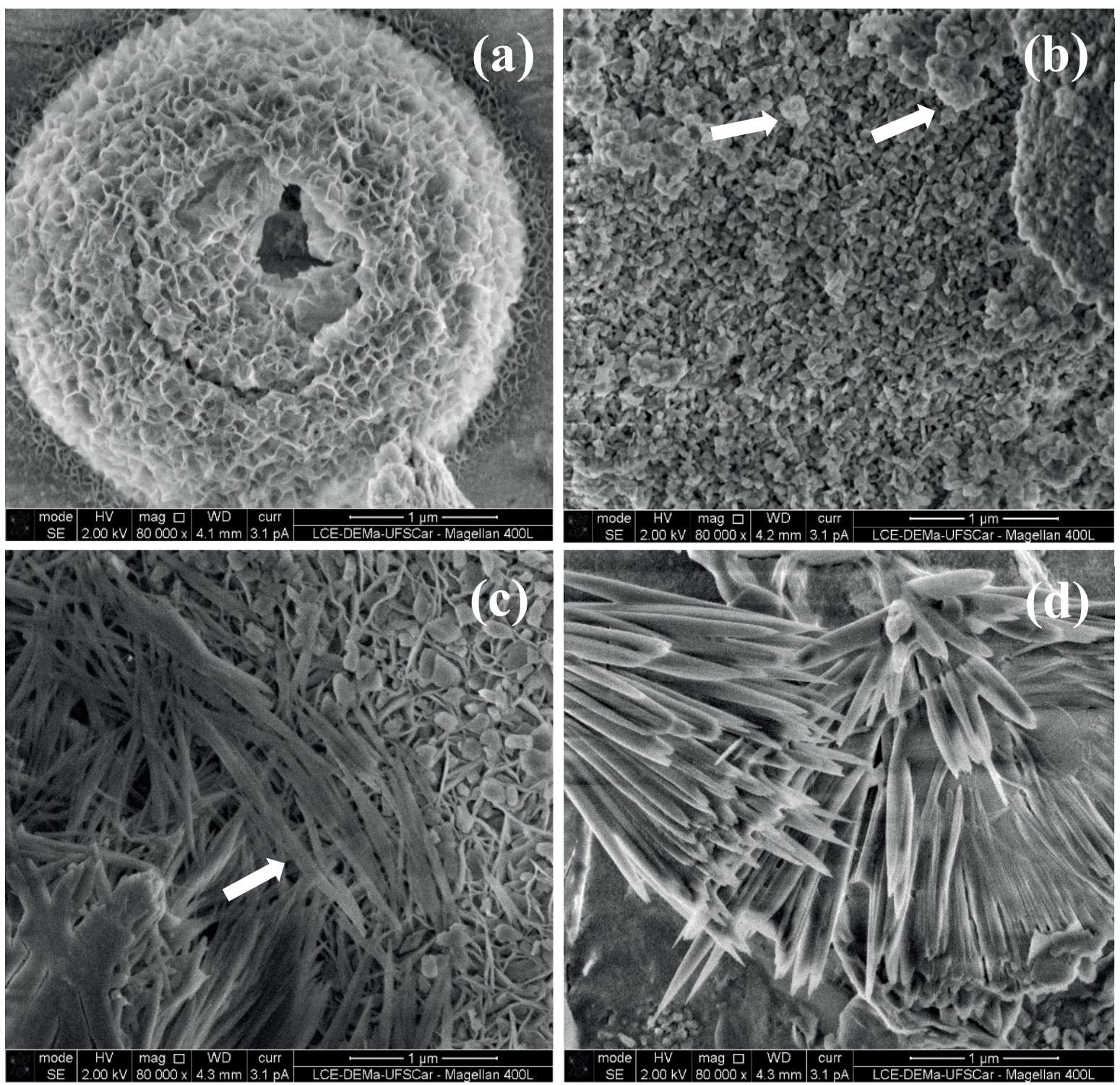

Figure 4. SEM micrographies of the $\mathrm{MgAl}$ mixed oxide (a), $5 \mathrm{Li}-\mathrm{MgAl}$ (b), $10 \mathrm{Li}-\mathrm{MgAl}$ (c) and $15 \mathrm{Li}-\mathrm{MgAl}$ (d).

the oxides sintering, an expressive reduction of the surface area and pore volume occurred with the Li addition into the MgAl mixed oxide. For example, the surface area of the $\mathrm{MgAl}$ is $155 \mathrm{~m}^{2} \mathrm{~g}^{-1}$ and it reduces to $<2 \mathrm{~m}^{2} \mathrm{~g}^{-1}$ for the 15 Li-MgAl (Table 1). This effect has also been reported for the $\mathrm{Li}-\mathrm{MgAl}$ oxides obtained by the co-precipitation route. It was observed that the surface area was reduced from 201 $\mathrm{m}^{2} \mathrm{~g}^{-1}$ (MgAl) to $5 \mathrm{~m}^{2} \mathrm{~g}^{-1}$ for the sample containing $10 \mathrm{wt} . \%$ Li (Castro et al., 2011).

The reduction of the catalyst surface areas with the $\mathrm{Li}$ addition into the oxides is not desired since the catalytic process is a surface phenomenon and, in theory, the higher the surface area, the higher the reactivity. However, the activity is also dependent on the presence of the active sites on the surface, more precisely, the density of active sites on the surface, expressed in $\mu \mathrm{mol} \mathrm{m} \mathrm{m}^{-2}$. Therefore, it is also important to investigate the presence of basic active sites on the surface of the Li-MgAl mixed oxides and this characterization was performed by TPD of $\mathrm{CO}_{2}$.

Figure 6 presents the TPD of $\mathrm{CO}_{2}$ characterization performed for $\mathrm{MgAl}$, 3-Li $\mathrm{MgAl}$ and 5-Li MgAl. In the next section it will be shown that the catalytic activity for 5, 10 and $15-\mathrm{Li} \mathrm{MgAl}$ is very similar. Thus, the basicity studies were performed only for the sample $5 \mathrm{Li}-\mathrm{MgAl}$ and the samples that presented no activity (3 Li-MgAl and $\mathrm{MgAl}$ ) for comparison.

The TPD of $\mathrm{CO}_{2}$ profile of the $\mathrm{MgAl}$ mixed oxide presented a low intensity desorption band at low temperature $\left(\approx 170^{\circ} \mathrm{C}\right)$, thus revealing that this oxide is mainly composed of weak basic sites related to surface 

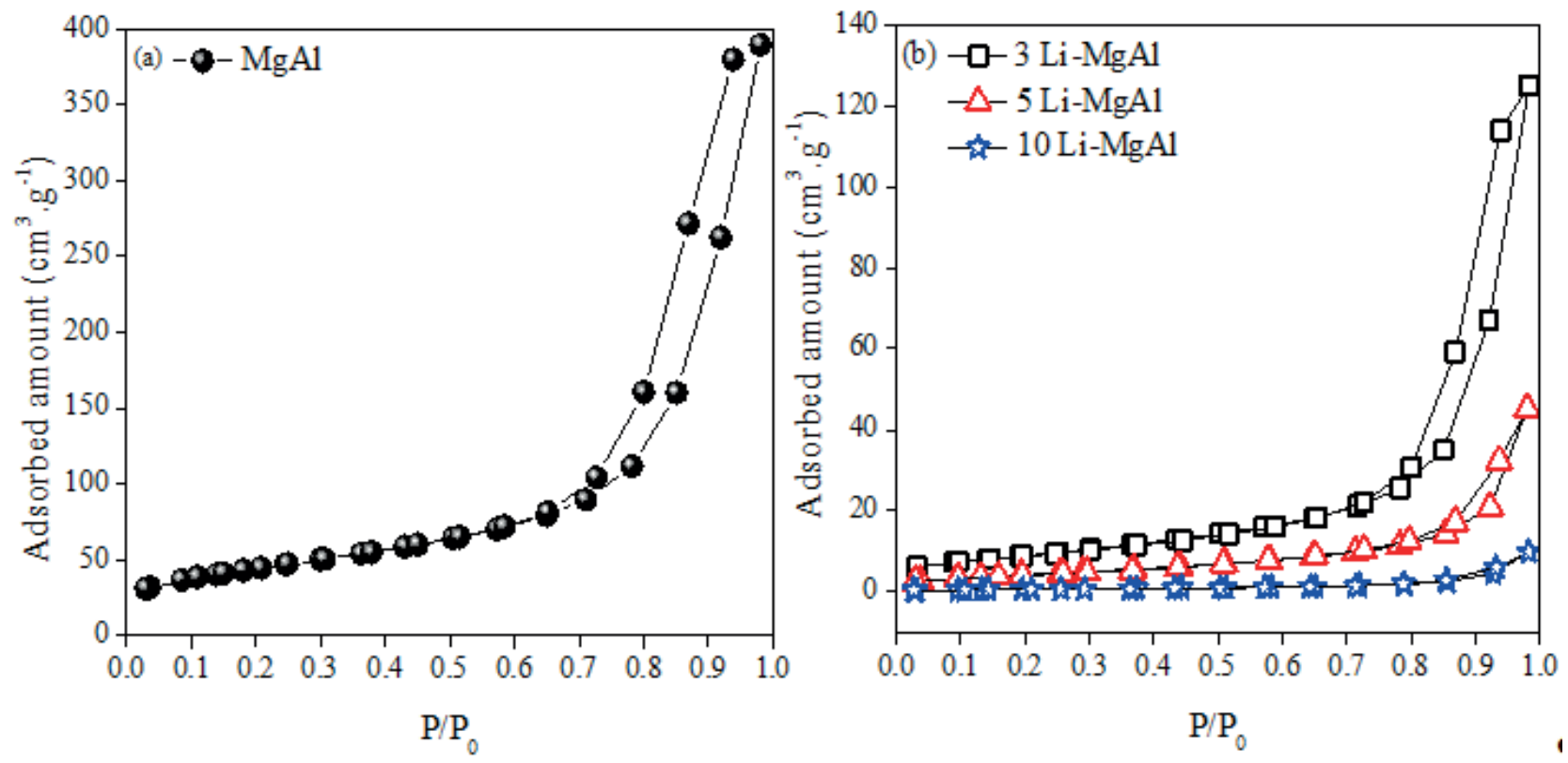

Figure 5. $\mathrm{N}_{2}$ adsorption/desorption isotherms at $77 \mathrm{~K}$ of the materials.

hydroxyl groups (Wang et al., 2012). By adding 3\% of $\mathrm{Li}$ into $\mathrm{MgAl}$, a broad desorption band centered at about $270^{\circ} \mathrm{C}$ is observed. This indicates that $\mathrm{Li}$ increased the density of the basic sites on the catalyst surface (observed by the area under the TPD curve) and increased the strength of the basic sites (verified by the $\mathrm{CO}_{2}$ desorption temperature; the higher the desorption temperature, the higher the basic strength). The medium strength basic sites are mainly associated with $\mathrm{Mg}^{2+}-\mathrm{O}^{2-}$ and $\mathrm{Al}^{3+}-\mathrm{O}^{2-}$ pairs (Díez et al., 2000) and possibly with $\mathrm{Li}^{+}-\mathrm{O}^{2-}$ pairs. These sites are present mainly on $3 \mathrm{Li}-\mathrm{MgAl}$. In the case of $5 \mathrm{Li}-$ $\mathrm{MgAl}$, besides the peak centered at $170^{\circ} \mathrm{C}$, a large amount of strong base sites (centered at $400^{\circ} \mathrm{C}$ ) can be clearly observed. The strong basic sites are probably attributed to isolated $\mathrm{O}^{2-}$ anions, of low coordination number, which are highly reactive (Díez et al., 2000; Díez et al., 2006).

The total basic site densities $\left(\mathrm{n}_{\mathrm{b}}\right)$ of the studied catalysts were measured by integration of $\mathrm{CO}_{2}$ TPD bands (Table 2). The TPD plots were deconvoluted into three desorption peaks with maximum desorption temperatures in the range of $160-190^{\circ} \mathrm{C}$ (weak base sites), $210-280^{\circ} \mathrm{C}$ (medium strength base sites) and $350-450^{\circ} \mathrm{C}$ (strong base sites). These results indicate that total $\mathrm{n}_{\mathrm{b}}$ has a maximum value for $5 \mathrm{Li}-\mathrm{MgAl}$ and decreases with the reduction of the Li loading on the materials. The $5 \mathrm{Li}-\mathrm{MgAl}$ oxide also showed the highest amount of strong base sites. It must be highlighted that the strong basic site density on sol-gel 5 $\mathrm{Li}-\mathrm{MgAl}\left(7.65 \mu \mathrm{mol} \mathrm{m}^{-2}\right)$ is even higher than that present on the $10 \mathrm{Li}-\mathrm{MgAl}$ catalyst prepared by co-precipitation $\left(3.90 \mu \mathrm{mol} \mathrm{m}^{-2}\right)$ (Castro et al., 2013).

\section{Catalytic evaluation}

The catalyst performances for the model transesterification are presented in Fig. 7. The symbols represent the average conversion values and the standard deviations are indicated by bars.

It is possible to observe that the $\mathrm{MgAl}$ mixed oxide and the sample containing the lowest Li loading (3 $\mathrm{Li}-\mathrm{MgAl}$ ) presented no activity. In contrast,

Table 1. Crystallite size, BET surface area and lithium loading in the catalysts.

\begin{tabular}{lllll}
\hline Catalysts & Crystallite size $(\mathrm{nm})$ & Surface area $\left(\mathrm{m}^{2} \mathrm{~g}^{-1}\right)$ & Pore volume $\left(\mathrm{cm}^{3} \mathrm{~g}^{-1}\right)$ & $\mathrm{Li}^{+}$loading $(\text {wt. } \%)^{* *}$ \\
\hline $\mathrm{MgAl}$ & 13.2 & 155 & 0.610 & - \\
$3 \mathrm{Li}-\mathrm{MgAl}$ & 18.7 & 62 & 0.200 & $3.2 \pm 0.10$ \\
$5 \mathrm{Li}-\mathrm{MgAl}$ & 18.9 & 16 & 0.072 & $4.2 \pm 0.07$ \\
$10 \mathrm{Li}-\mathrm{MgAl}$ & 22.6 & 2 & 0.016 & $6.5 \pm 0.28$ \\
$15 \mathrm{Li}-\mathrm{MgAl}$ & 27.8 & $<2 *$ & $<0.016$ & $7.7 \pm 0.35$ \\
\hline
\end{tabular}

a Obtained from XRD and Sherrer's Equation using the main diffraction peak of MgAl at $2 \theta=43.0^{\circ}$.

* The surface area of the $15 \mathrm{Li}-\mathrm{MgAl}$ was not determined since it was too small $\left(<2 \mathrm{~m}^{2} \mathrm{~g}^{-1}\right)$.

** Determined by Atomic Emission Spectrometer. 


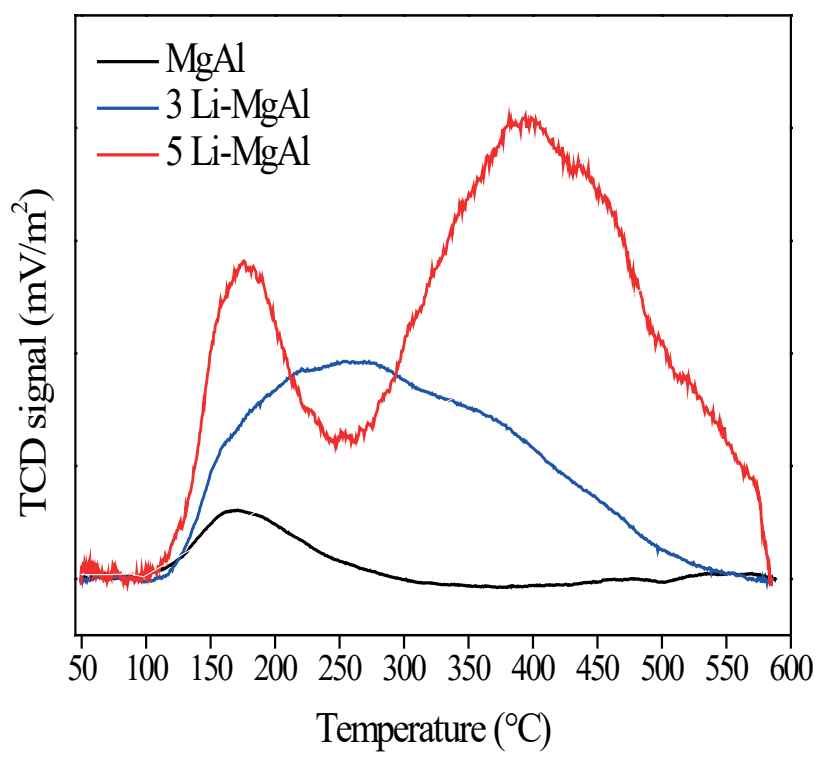

Figure 6. Temperature-programmed desorption profiles of $\mathrm{CO}_{2}$ of the sol-gel MgAl and Li-MgAl mixed oxides.

Table 2. Basic site density for $\mathrm{MgAl}$ and $\mathrm{Li}-\mathrm{MgAl}$ mixed oxides.

\begin{tabular}{ccccc}
\hline \multirow{2}{*}{ Catalysts } & \multicolumn{4}{c}{ Density of base sites $-\mathrm{n}_{\mathrm{b}}\left(\mu \mathrm{mol} \mathrm{m} \mathrm{m}^{-2}\right)$} \\
\cline { 2 - 5 } & ${\text { Total } \mathrm{n}_{\mathrm{b}}}$ & Weak $\mathrm{n}_{\mathrm{b}}$ & Medium $\mathrm{n}_{\mathrm{b}}$ & Strong $\mathrm{n}_{\mathrm{b}}$ \\
\hline MgAl & 0.54 & 0.42 & 0.13 & 0.00 \\
$3 \mathrm{Li}-\mathrm{MgAl}$ & 4.23 & 0.22 & 1.79 & 2.22 \\
$5 \mathrm{Li}-\mathrm{MgAl}$ & 9.16 & 1.34 & 0.17 & 7.65 \\
\hline
\end{tabular}
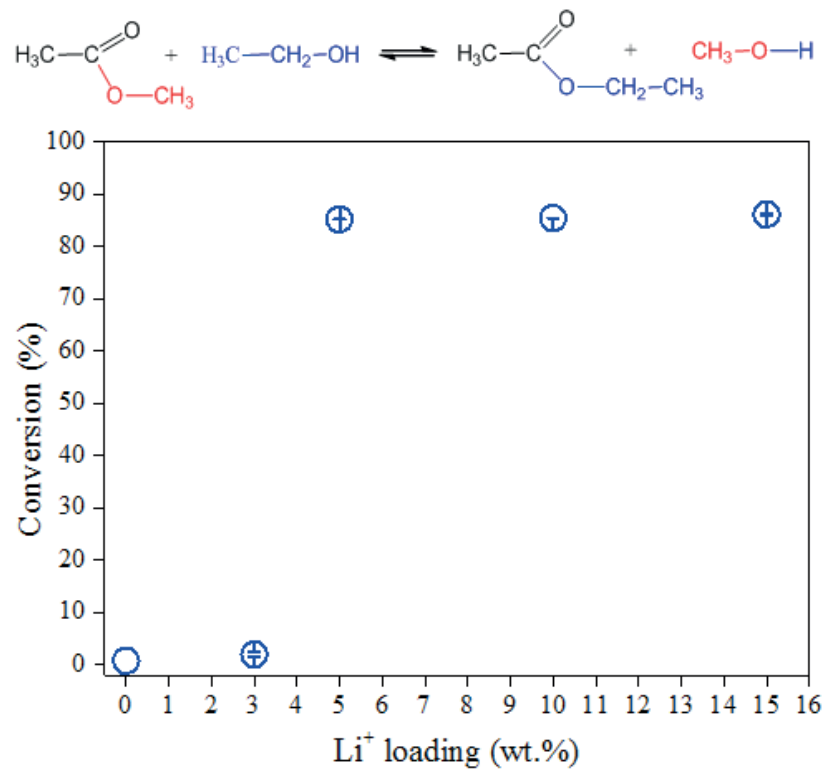

Figure 7. Transesterification reaction in the presence of the sol-gel $\mathrm{MgAl}$ mixed oxide and $\mathrm{Li}$ containing $\mathrm{MgAl}$ oxides. the oxides with higher $\mathrm{Li}$ loadings (5, 10 and $15 \mathrm{Li}-\mathrm{MgAl}$ ) exhibited high conversions, irrespective of the $\mathrm{Li}$ content. The catalytic results revealed that the activity for transesterification is strictly dependent on the presence of $\mathrm{Li}$ in the mixed oxides, since the catalyst without $\mathrm{Li}(\mathrm{MgAl})$ presented no activity. In addition, the activity is dependent on the Li loading on the catalysts.

This finding further supports the idea that $\mathrm{Li}$ is crucial in the creation of the active sites for transesterification. Although the surface area reduction occurred with the $\mathrm{Li}$ addition to the catalysts, the density of basic sites ( $\mu \mathrm{mol}$ $\mathrm{m}^{-2}$ ) markedly increased and this resulted in the enhanced catalytic performance for transesterification.

The TPD of $\mathrm{CO}_{2}$ characterization revealed that the $\mathrm{Li}$ addition to the catalysts increased the total density of basic sites and, which seems to be more important, the density of strong basic sites. This can explain the sharp conversion increase observed when the Li loading on the catalyst increased from 3 to 5 wt.\% (Fig. 7). The 3 Li$\mathrm{MgAl}$ presents mainly basic sites of medium strength, leading to negligible conversion. On the other hand, $5 \mathrm{Li}-$ $\mathrm{MgAl}$ presents a lot of strong basic sites, which resulted in high activity. Table 3 presents the turnover frequencies for the catalysts, which were calculated based on the strong basic sites. Considering the fact that the $\mathrm{MgAl}$ catalyst does not present basic sites of high strength (Table 2), the TOF value for this catalyst was not calculated. As shown in Table 3, a value 45-fold greater was obtained for $5 \mathrm{Li}$ $\mathrm{MgAl}$ compared to the TOF value for $3 \mathrm{Li}-\mathrm{MgAl}$, and these values are within the expected range for most reactions involving heterogeneous catalysis (i.e., from $10^{-2}$ to $10^{2} \mathrm{~s}^{-1}$ ) (Thomas and Thomas, 1996).

Therefore, the results suggest that the strong basic sites, mainly associated with isolated $\mathrm{O}^{2-}$ anions are possibly the active sites for transesterification in the case of $\mathrm{Li}-\mathrm{MgAl}$ mixed oxides. These isolated $\mathrm{O}^{2-}$ of low coordination are related to surface defects formed during the $\mathrm{Mg}^{2+}$ substitution by $\mathrm{Li}^{+}$due to their ionic radii similarity.

The great performance of the $\mathrm{Li}$ based $\mathrm{MgAl}$ oxides prepared by the co-precipitation route has already been reported in our previous papers (Castro et al., 2011; Castro et al., 2013). However, in the case of Li-MgAl oxides prepared by the sol-gel method, the Li loading required for activity is quite low, reaching about $85 \%$ of conversion with the catalyst containing only 5 wt.\% Li. For coprecipitated samples, the Li loading required to achieve the same conversion was 10 wt.\% Li (Castro et al., 2011).

Table 3. Turnover frequency (TOF) for model transesterification in the presence of the $\mathrm{MgAl}$ and $\mathrm{Li}-\mathrm{MgAl}$ catalysts.

\begin{tabular}{cc}
\hline Catalysts & TOF $\left.\mathbf{x 1 0}^{\mathbf{3}} \mathbf{( s}^{-\mathbf{1}}\right)$ \\
\hline $\mathrm{MgAl}$ & - \\
$3 \mathrm{Li}-\mathrm{MgAl}$ & 5.9 \\
$5 \mathrm{Li}-\mathrm{MgAl}$ & 275.0 \\
\hline
\end{tabular}


This indicates that the Li interaction with HT prepared by the sol-gel route is different from that of the coprecipitated HT followed by Li impregnation. This is also evidenced by the changes caused in the morphology of the sol-gel and coprecipitated oxides. The in situ $\mathrm{Li}$ addition during the sol-gel HT synthesis increased the number of defects in the lattice of MgAl mixed oxide after calcination due to the closer Li interaction with the HT matrix when compared to the Li impregnation on the surface of co-precipitated HT.

\section{Stability studies}

The stability of the sol-gel Li-MgAl catalysts was investigated through its recycling and reuse during consecutive batch runs. The experiments were performed with the active catalysts for transesterification and the results are presented in Fig. 8. Vertical bars in each column represent one stardard deviation.

It can be clearly observed that, irrespective of the $\mathrm{Li}$ content, the catalysts lost their activity during recycling (Fig. 8-a). The conversion was reduced severely in the third reaction cycle. In an attempt to increase the catalyst stability, a representative sample of $15 \mathrm{Li}-\mathrm{MgAl}$ was calcined at a higher temperature of $700^{\circ} \mathrm{C}$. The reuse experiments are shown in Fig. 8-b. Although the conversion increased slightly in the second and third runs, an apparent deactivation still occurs. It seems that, even though the $\mathrm{Li}$ interaction with the sol-gel $\mathrm{MgAl}$ oxide were different from the co-precipitated catalysts, a similar deactivation profile was observed, possibly due to the leaching phenomenon. Chemical analysis results for the 10 $\mathrm{Li}-\mathrm{MgAl}$ sample revealed that lithium leaching to solution occurs, since approximately $500 \mathrm{mg} \mathrm{L}^{-1}$ of $\mathrm{Li}^{+}$was detected in the reaction mixture after the first reaction cycle.

\section{CONCLUSIONS}

The use of the sol-gel method for the synthesis of the Li-MgAl mixed oxides led to the formation of highly active catalysts for the model transesterification reaction. These materials were as active as the same oxides prepared by coprecipitation. However, the lithium loading required to reach the same conversion was 2-fold lower in the case of sol-gel samples. This result indicates that the $\mathrm{Li}$ interaction with the $\mathrm{MgAl}$ matrix is different when using the sol-gel route. This finding is supported by the morphological differences between the sol-gel (needle-like particles) and coprecipitated (round aggregates) samples. The catalyst performances for transesterification are closely related with the basicity of the catalysts. The conversion were dependent on the Li loading on the catalysts and related to the density of the strong basic sites on the catalysts. The strong basic sites in $\mathrm{Li}-\mathrm{MgAl}$ are possibly related to $\mathrm{O}^{2-}$ anions of low coordination that are probably the active sites for reaction. The results of this study suggest that the very active sol-gel Li-MgAl catalysts are promising candidates to replace the homogeneous catalysts industrially used for transesterification. Nevertheless, the stability tests revealed that the catalysts reduce their activity during recycling. Further research should be carried out in order to investigate possible modifications in the synthesis procedure in an attempt to increase the $\mathrm{Li}-\mathrm{MgAl}$ mixed oxides stability.
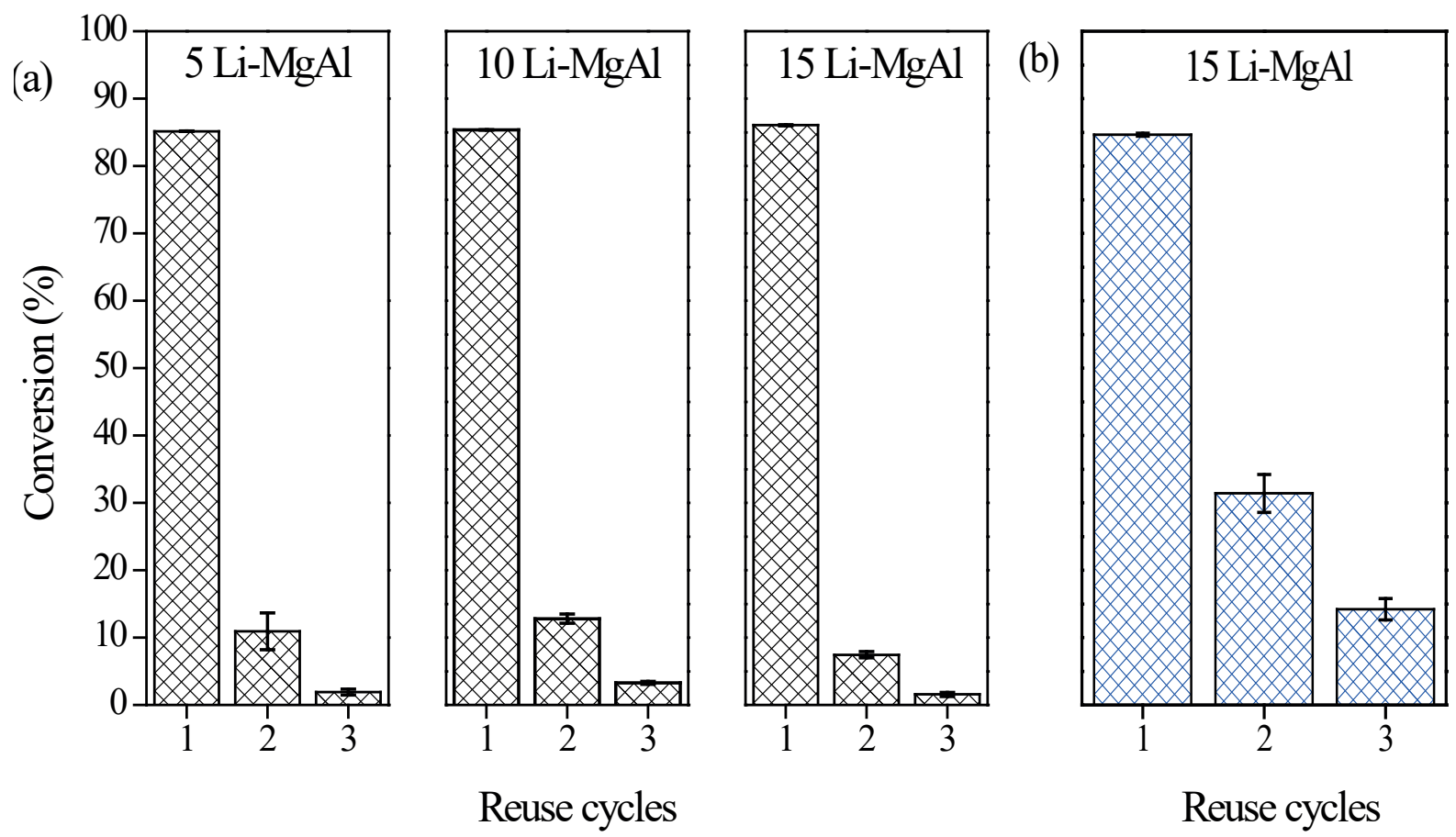

Figure 8. Reuse cycles for the transesterification reaction in the presence of the $\mathrm{Li}-\mathrm{MgAl}$ oxides calcinated at $600^{\circ} \mathrm{C}(\mathrm{a})$ and $700^{\circ} \mathrm{C}(\mathrm{b})$. 


\section{ACKNOWLEDGEMENTS}

The authors are grateful to the Conselho Nacional de Desenvolvimento Científico e Tecnológico-CNPq (Brazil) for financial support (process numbers 151498/2013-0 and 500251/2013-4).

\section{REFERENCES}

Aransiola, E.F., Ojumu, T.V., Oyekola, O.O., Madzimbamuto, T.F. and Ikhu-Omoregbe, D.I.O., A review of current technology for biodiesel production: state of the art, Biomass Bioenergy, 61, 276-297 (2014).

Barbosa, C.A.S., Dias, P.M., Ferreira, A.M.C. and Constantino, V.R.L., Mg-Al hydrotalcite-like compounds containing ironphthalocyanine complex: effect of aluminum substitution on the complex adsorption features and catalytic activity, Appl. Clay Sci., 28, 147-158 (2005).

Bart, J.C.J., Palmeri, N. and Cavallaro, S., Biodiesel Science and Technology: from soil to oil. Woodhead Publishing Limited, Boca Raton, ch. 7, 285-321 (2010).

Berger, T., Schuh, J., Sterrer, M., Diwald, O. and Knözinger, E., Lithium ion induced surface reactivity changes on $\mathrm{MgO}$ nanoparticles, J. Catal., 247, 61-67 (2007).

Castro, C.S., Cardoso, D., Nascente, P.A.P. and Assaf, J.M., MgAlLi mixed oxides derived from hydrotalcite for catalytic transesterification, Catal. Lett., 141, 1316-1323 (2011).

Castro, C.S., Ferreti, C., Di Cosimo, J.I. and Assaf, J.M., Support influence on the basicity promotion of lithium-based mixed oxides for transesterification reaction, Fuel, 103, 632-638 (2013).

Castro, C.S., Garcia Júnior, L.C.F. and Assaf, J.M., The enhanced activity of $\mathrm{Ca} / \mathrm{MgAl}$ mixed oxide for transesterification, Fuel Process. Technol., 125, 73-78 (2014).

Chen, J., Jia, L., Guo, X., Xiang, L. and Lou, S., Production of novel biodiesel from transesterification over KF-modified CaAl hidrotalcite catalyst, RSC Adv., 4, 60025-60033 (2014).

Di Cosimo, J.I., Díez, V.K. and Apesteguía, C.R., Synthesis of $\alpha, \beta$-unsaturated ketones over thermally activated $\mathrm{Mg}-\mathrm{Al}$ hydrotalcites, Appl. Clay Sci., 13, 433-449 (1998).

Di Serio, M., Mallardo, S., Carotenuto, G., Tesser, R. and Santacesaria, E., Mg/Al hydrotalcite catalyst for biodiesel production in continuous packed bed reactors, Catal. Today, 195, 54-58 (2012).

Díez, V.K., Apesteguía, C.R., Di Cosimo, J.I., Acid-base properties and active site requirements for elimination reactions on alkalipromoted $\mathrm{MgO}$ catalysts, Catal. Today, 63, 53-62 (2000).

Díez, V.K., Apesteguía, C.R. and Di Cosimo, J.I., Aldol condensation of citral with acetone on $\mathrm{MgO}$ and alkalipromoted MgO catalysts, J. Catal., 240, 235-244 (2006).

Guzmán-Vargas, A., Santos-Gutiérrez, T., Lima, E., FloresMoreno, J.L., Oliver-Tolentino, M.A. and Martínez-Ortiz, M.J., Transesterification of rapeseed oil by $\mathrm{Mg}-\mathrm{Al}$ mixed oxides with various $\mathrm{Mg} / \mathrm{Al}$ molar ratio, J. Alloys Compd., 643, S159-S164 (2015).

Hájek, M., Kutálek, P., Smoláková, L., Troppová, I., Čapek, L., Kubička, D., Kocík, J. and Thanh, D.N., Transesterification of rapeseed oil by $\mathrm{Mg}-\mathrm{Al}$ mixed oxides with various $\mathrm{Mg} / \mathrm{Al}$ molar ratio, Chem. Eng. J., 263, 160-167 (2015).

Hanna, M.A. and Isom, L., Handbook of plant-based biofuels. CRC Press, Boca Raton, ch. 12, 177-182 (2009).

Lide, D.R. Handbook of Chemistry and Physics: a ReadyReference Book of Chemical and Physical Data. CRC Press, Boca Raton (1997).

Lima, E., Martínez-Ortiz, M.J., Reyes, R.I.G. and Vera, M., Fluorinated hydrotalcites: the addition of highly electronegative species in layered double hydroxides to tune basicity, Inorg. Chem., 51, 7774-7781 (2012).

Lopez, T., Ramos, E., Bosch, P., Asomoza, M. and Gomez, R., DTA and TGA characterization of sol-gel hydrotalcites, Mater. Lett., 30, 279-282 (1997).

Prinetto, F., Ghiotti, G., Graffin, P. and Tichit, D., Synthesis and characterization of sol-gel $\mathrm{Mg} / \mathrm{Al}$ and $\mathrm{Ni} / \mathrm{Al}$ layered double hydroxides and comparison with co-precipitated samples, Microporous Mesoporous Mater., 39, 229-247 (2000).

Ramos-Ramírez, E., Ortega, N.L.G., Soto, C.A.C. and Gutiérrez, M.T.O., Adsorption isotherm studies of chromium (VI) from aqueous solutions using sol-gel hydrotalcite-like compounds, J. Hazard. Mater., 172, 1527-1531 (2009).

Reichle, W.T., Kang, S.Y. and Everhardt, D.S., The nature of the thermal decomposition of a catalytically active anionic clay mineral, J. Catal., 101, 352-359 (1986).

Rynkowski, J., Kaźmierczak, A., Praźmowska-Wilanowska, A. and Paryjczak, T., Influence of calcinations and lithium promotion on the surface properties of oxide supports, React. Kinet. Catal. Lett., 58, 169-175 (1996).

Serrano-Lotina, A., Rodríguez, L., Muñoz, G. and Daza, L., Biogas reforming on La-promoted $\mathrm{NiMgAl}$ catalysts derived from hydrotalcite-like precursors, J. Power Sources, 196, 4404-4410 (2011).

Sing, K.S.W., Haul, R.A.W., Pierotti, R.A. and Siemieniewska, T., Reporting physisorption data for gas/solid systems with special reference to the determination of surface area and porosity, Pure Appl. Chem., 57, 603-619 (1985).

Sun, J., Yang, J., Li, S. and $\mathrm{Xu}, \mathrm{X}$., Basicity-FAME yield correlations in metal cation modified $\mathrm{MgAl}$ mixed oxides for biodiesel synthesis, Catal. Commun., 52, 1-4 (2014).

Tittabut, T. and Trakarnpruk, W., Metal-loaded MgAl oxides for transesterification of glyceryl tributyrate and palm oil, Ind. Eng. Chem. Res., 47, 2176-2181 (2008).

Thomas, J.M. and Thomas, W.J. Principles and Practice of Heterogeneous Catalysis. VCH, Weinheim (1996).

Veiga, P.M., Sousa, Z.S.B., Polato, C.M.S., Portilho, M.F., Veloso, C.O. and Henriques, C.A., Influence of the incorporation of transition metals on the basicity of $\mathrm{Mg}, \mathrm{Al}$-mixed oxides and on their catalytic properties for transesterification of vegetable oils, J. Catal., 2013, 1-10 (2013).

Wang, S.-H., Wang, Y.-B., Dai, Y.-M. and Jehng, J.-M., Preparation and characterization of hydrotalcite-like compounds containing transition metals as solid base catalysts for the transesterification, Appl. Catal., A, 439-40, 135-141 (2012).

Xie, W., Peng, H. and Chen, L., Calcined Mg-Al hydrotalcites as solid base catalysts for methanolysis of soybean oil, J. Mol. Catal. A: Chem., 246, 24-32 (2006). 